\title{
Lichen progenitalis.
}

\section{Von Dr. J. Broers, Arzt für Hautkrankheiten im Haag (Holland).}

Dr. A.Sackis Mitteilung in dieser Wochenschrift (3. Dezember 1903) über Fälle von isoliertem Lichen buccalis veranlaßt mich, über einen Fall von Lichen zu berichten, den ich Ende 1902 sah und der sich vor allem an den Schleimhäuten des Penis manifestierte, wodurch der Patient sich beunruhigte und auch der behandelnde Arzt betreffs der Diagnosestellung in Verlegenheit kam.

Es betraf einen verheirateten, 56 jährigen Mann, ohne wichtige Antezedentien, der seit dem Frühjahr 1902 an einem Ausschlage an der Glans penis litt, den er beschrieb als weiß gefärbt, in der Form von Verästelungen ausgehend von der Corona und nach vorn sich verbreitend; an einigen Stellen entstanden sehr kleine Bläschen, welche platzten und durch medikamentöse Behandlung oder spontan heilten, aber unablässig von anderen gefolgt wurden, sodaß Patient jedesmal in seiner Hoffnung, genesen zu sein, getäuscht wurde. Der Ausschlag war von Juckreiz begleitet, welcher speziell im Anfang sehr belästigend war. Dazu bekam er auf der äußeren Seite der Vorhaut eine Eruption, nach seiner Angabe ebenso von Bläschen. Im Juli desselben Jahres zeigten sich weiße Flecke an der Schleimhaut der Wrangen und der Zunge und einige Wochen später einzelne Effloreszenzen an beiden Achseln, welche gelegentlich juckten. Diese letzteren zeigte er seinem Hausarzte nicht, weil er sie für bedeutungslos hielt und sich nur wegen der Affektion am Penis ängstigte. Trotz Anwendung von adstringierenden Lösungen, Pulvern und Salben änderte sich, wie gesagt, dieser Zustand nicht, und darum sprach der Hausarzt mit mir über diesen Fall, der, obwohl der Kollege geneigt war, an Herpes progenital is zu denken, nach seiner Meinung davon abweichende Erscheinungen darbot.

Als ich den Patienten Anfang Oktober sah, zeigte er im Sulcus retroglandularis ein paar nadelkopfgroße, einigermaßen eiternde Epitheldefekte und am Frenulum ein kleines oberflächliches Geschwür ohne die mindeste Infiltration der Umgebung; an der Innenseite des Praeputiums, das zurïckgezogen war zur Entblößung der Glans, war deutlich eine weiße Marmorierung des Epithels zu sehen; an der Eichel selbst war außer im Sulcus und an der Corona nahezu nichts mehr übrig von einer ähnlichen Marmorierung, mit der nach Angabe des Patienten die Krankheit angefangen hatte. - An der Vorderseite der äußeren Platte der Vorhaut saß eine erbsengroße, schwach infiltrierte, braunrote weißgestreifte, schuppende Papel. - Die Leistendrüsen waren beiderseits palpierbar, die Palpation ließ aber keine besonderen Schlüsse zu. Der ganze Körper war frei von Ausschlag, nur an den beiden Achseln zeigten sich einige dunkelrote, leicht erhabene, halbpfennigstückgroße und auch kleinere Effloreszenzen, in deren wachsartig glänzendem Kolorit ein weißes Netzwerk deutlich sichtbar war. Bei der Inspektion des Mundes erwies sich das Epithel der Zunge und der Wangen bedeckt mit etwas erhabenen, weißen, geschlängelten, untereinander ein Netzwerk formenden Linien. Der Patient klagte über ein unbestimmtes unangenehmes Gefühl an der Glans penis, das er nicht näher definieren konnte und etwas anderes war als Jucken; dagegen juckte die kleine Stelle an der Außenseite des Praeputiums stark; an den Achseln spürte er wenig und auch 
die Veränderungen im Munde machten ihm kaum Beschwerden, nur war die Zunge etwas empfindlich gegen heiße Speisen und Getränke. - Damals war es also nicht zweifelhaft, daß dies ein Fall von Lichen ruber planus war, das hauptsächlich auf die Schleimhäute lokalisiert war

Das leukoplakiaähnliche Lichen der Mundschleimhaut kommt oft vor, an den Schleimhäuten der Genitalien ist es seltener, ganz besonders beim Manne, weil die Papeln an der Glans gewöhnlich wie Hautpapeln aussehen; beim Weibe trifft man es dagegen nicht allzu selten an den Labia minora an. Ein einziges Mal ist eine derartige Veränderung an der Schleimhaut des Anus [K. Marx'], des Larynx [Lukasiewicz $\left.\left.{ }^{2}\right)\right]$ und der Urethra [Heuss $\left.\left.{ }^{3}\right)\right]$ beschrieben worden.

Obgleich die solide Papel das Kennzeichen vom Lichen ist, kornmen bei dieser Hautkrankheit bisweilen allch kleinere oder größere Blasen vor ${ }^{4}$, in den meisten Fallen ist dies die Folge eines Uberganges der Papel in eine Blase, obwohl auch Beobachtungen sich vorfinden, daß Lichen gleichzeitig mit Herpes zoster vorkam [Pringle ${ }^{5}$ )]. Es ist also möglich, daß in casu ein Zusammentreffen von Lichen mit Herpes progenitalis vorlag. - Einige Autoren haben gemeint, die Bildung ron Blasen beim Lichen dem dargereichten Arsenicum, einem beliebten Heilmittel gegen diese Krankheit, zuschreiben zu müssen, aber Kaposi, Besnier u. a. sahen diese doch auch auftreten, bevor eine Arsenicumkur angefangen hatte. Unser Patient hatte bestimmt kein Arsenicum genommen.

Dieser Fall schien mir also der Mitteilung wert, weil die Schleimhautaffektion das Krankheitsbild, besonders im Anfang, ganz beherrschte und außerdem durch das Auftreten von Bläschen das Stellen einer richtigen Diagnose mit einigen Schwierigkeiten verbunden war. 